Transaction of the Materials Research Society of Japan 34[2] 221-224 (2009)

\title{
Synthesis and characterization of zinc oxide from absorption of carbon dioxide
}

\author{
Pao-Chi Chen* and Jun Jie Wu \\ Department of Chemical and Materials Engineering \\ Lunghwa University of Science and Technology \\ 300, Wan-Shou Rd., Sec. 1, Kueishan, Taoyuang, Taiwan, 333 \\ E-mail:chenpc@mail2000.com.tw
}

\begin{abstract}
A pH-stat continuous-bubble-column scrubber using $\mathrm{CO}_{2}-\mathrm{Zn}\left(\mathrm{NO}_{3}\right)_{2}-\mathrm{NaOH}$ as a reacting system was used to prepare the precursors of $\mathrm{ZnO}$. The experiments were carried out in the $\mathrm{pH}$ range of $10-13$ and in the gas-flow rate range of 3-8 $\mathrm{L} / \mathrm{min}$. The process favored the formation of zinc carbonate hydroxide hydrate at lower $\mathrm{pH}$ values and/or higher gas-flow rates, while the major precursor was hydroxide hydrate at higher $\mathrm{pH}$ values. To quantitatively determine the composition of precursors, the powders were examined by XRD analysis. Also, the decomposition temperatures of precursors were observed from thermal analysis. Examinations of photoluminescence (PL), XRD, and BET for nano-zinc oxide particles obtained in here are required and the results are compared with that standard zinc oxide powders.
\end{abstract}

\section{Introduction}

Znic oxide is an important material, which can be used as semiconductor, pigments, rubber additive, gas sensor, varistors, photocatalysis and optical devices. Synthesis of zinc oxide in nano-size was carried out by various methods [1-8]. In the synthesis of zinc oxide, there are three points must be faced: first, quality of particles second, energy consideration; third, green technology. However, no available process in the preparation of zinc oxide was found in the literature including the three points. Due to this, absorption of carbon dioxide with alkaline solution containing zinc ion in bubble column was used here to obtain precursors of zinc oxide [9].

The major variables explored here are the $\mathrm{pH}$ of the solution and gas-flow rate. The decomposition temperature of intermediated phase was examined by using TGA/DSC analysis. In addition, the composition of intermediated phase was quantified by XRD analysis. The properties of calcined particles were characterized by using SEM, PL, XRD, and BET specific surface area, respectively. The result was also compared with standard $\mathrm{ZnO}$.

\section{Experimental Section}

The experimental feature for the absorption of carbon dioxide accompanying with precipitation is similar to that in previous work [9]. During the operation, the $\mathrm{Zn}\left(\mathrm{NO}_{3}\right)_{2}$ solution was fed into the column continuously and reacted with carbon dioxide. The $\mathrm{pH}$ of the solution decreased due to absorption and crystallization in the scrubber. In order to hold the $\mathrm{pH}$ value of the solution, a known concentration of $\mathrm{NaOH}$ solution was introduced into the column through the action of a pH-controller. The overflow slurry was flowing out to the reservoir. A Gas Data $\mathrm{PCO}_{2}$ Meter was used to measure the concentration of the $\mathrm{CO}_{2}$-gas at the outlet of the bubble column. When the concentration of $\mathrm{CO}_{2}$-gas became steady state, the slurry was withdrawn using a syringe and divided into two parts for the 
measurements of TOC, zinc ion concentration and crystal size distribution, respectively. The experiments were conducted at $30^{\circ} \mathrm{C}$ in most of the runs, and the operational $\mathrm{pH}$ values were kept within the range of 10 to 13 . The operating time was 120 minutes for each run. At the end of the operations, the slurry was filtered and the volume of filtrate $\left(\mathrm{V}_{\mathrm{L}}\right)$ was measured. Subsequently, the solids were dried in an oven at $100^{\circ} \mathrm{C}$ at least 1 hour. The dried solids were examined by using XRD, TGA/DSC, and SEM, respectively. In addition, the dried solids were decomposed further in an oven at a given temperature for 3 hours to prepare zinc oxide powders. The calcined powders were characterized by XRD, PL, SEM, and BET instruments, respectively.

\section{Results and discussion}

\section{Characterization of precursors}

Two kinds of precursors were observed here ; one is zinc carbonate hydroxide hydrate (A-phase) and another is zinc hydroxide (B-phase), depending on the operating conditions. The compositions of solids were examined by XRD analysis as shown in Figure 1. The lower peaks were close to the values that found in JCPDS for A-phase, which was comparable to that reported in the literature [10]. However, the upper peaks have two kinds of peaks for B-phase were found in XRD patterns as also compared with standard card exhibiting as $\mathrm{Zn}(\mathrm{OH})_{2}$ and wülfingite.

The compositions of mixture representing as component A was also analyzed quantitatively by XRD method. A plot of weight fraction of $A\left(w_{A}\right)$ versus $\mathrm{pH}$ at various gas-flow rates was shown in Figure 2. The results showed that pure A-phase was observed at $\mathrm{pH}$ of 10 , while B-phase was the major product as the $\mathrm{pH}$ value was higher than 12.5. A mixture of $A$ and $B$ was found when the
$\mathrm{pH}$ was in the range of 10.5 to 12.5 .

Figure 3 were the TGA/DSC analysis for different precursors. The first exothermic peak for A-phase from DSC analysis was at temperature around $70^{\circ} \mathrm{C}$. This decomposition stage was possibly due to the release of hydrate water. The second stage weight loss was observed in the temperature range of 175 to $250^{\circ} \mathrm{C}$. The second exothermic peak was found at temperature around $200^{\circ} \mathrm{C}$. The loss of this step was ascribed to the release of carbonate ions. On the other hand, only one exothermic peak for B-phase was found and the decomposition was observed around $140^{\circ} \mathrm{C}$. From TGA analyses, it showed that the decomposition temperatures of precursors were $260^{\circ} \mathrm{C}$ and $150^{\circ} \mathrm{C}$ for pure $\mathrm{A}$ and pure $\mathrm{B}$, respectively. In order to decompose the precipitates completely, except pure $\mathrm{B}$, the calcinations for mixed precursors $(\mathrm{A}+\mathrm{B})$ and pure $\mathrm{A}$ were carried out at the temperature of $260^{\circ} \mathrm{C}$.

\section{Characterization of zinc oxide}

Calcined solids were examined by XRD analysis as shown in Figure 4. The patterns showed that the solids were zinc oxide as compared with standard pattern. Figure 5 showed the SEM photographs of $\mathrm{ZnO}$ obtained from precursors of $\mathrm{A}$ and $\mathrm{B}$ at different decomposition temperatures. Figure 6 was a plot of specific surface area $(\mathrm{S})$ versus $\mathrm{pH}$ value at various gas-flow rates, showing a minimum value. The reason was that precursors obtained in the $\mathrm{pH}$ range of 10.5 to 12.5 were a mixture of $\mathrm{A}$ and $\mathrm{B}$ as shown in Figure 2. In order to decompose precursors into $\mathrm{ZnO}$ completely, the calcination temperature was set at $260^{\circ} \mathrm{C}$. Due to this, a part of $\mathrm{B}$ existed in the mixture was calcined at the temperature of $260^{\circ} \mathrm{C}$ resulting in coarsening the grain of zinc oxide and hence reducing in specific surface area. 
The particle size could be estimated by means of specific surface area (S). The sizes obtained in this manner were in the range of 40 to $100 \mathrm{~nm}$. In addition, the particle sizes could be estimated by Scherer's equation according to XRD data $[1,11]$. The estimated sizes were in the range of 20 to $50 \mathrm{~nm}$, which were smaller than that obtained from $\mathrm{S}$. The difference was due to that the estimated values from Scherer's equation were primary particle size, while the estimated values obtained from $\mathrm{S}$ were average particle size, indicating the formation of agglomerates.

From photoluminescence (PL) spectrum shown in Figure 7, the green emission for zinc oxide obtained from A-phase was similar to that obtained in the standard powder, but no UV emission was observed between them. Besides, the PL spectrum obtained from B-phase was different from that obtained from A-phase, except green emission. The green-yellow emission was also obvious within the wavelength range of 500 to $600 \mathrm{~nm}$. In addition, the PL spectrum showed a weak UV emission.

\section{Conclusion}

Two kinds of precursors, A-phase and B-phase, were obtained in the absorption of $\mathrm{CO}_{2}$ with alkaline zinc ion solution using a $\mathrm{pH}$-stat continuous-bubble-column scrubber. At the $\mathrm{pH}$ of 10 A-phase was the major product, while B-phase was the major product when the $\mathrm{pH}$ was higher than 12.5. The compositions of precipitates could be determined quantitatively by using XRD analysis. Zinc oxide powders could be obtained from both A and B phases at the decomposition temperatures of $260^{\circ} \mathrm{C}$ and $150^{\circ} \mathrm{C}$, respectively. Particle sizes for zinc oxide could be determined by both Scherer's equation and BET specific surface area. The BET specific surface area presented minimum value in the $\mathrm{pH}$ range of 11-11.5, indicating that coarsening particles was occurred during the calcinations. Examinations of PL, XRD, and BET showed that nano-zinc oxide particles obtained for A-phase were similar to that obtained from standard zinc oxide powders. Besides, the PL showed that zinc oxide obtained from B-phase was exhibited green-yellow emission. Finally, the process not only could be used to capture carbon dioxide, but also could obtain nano-zinc oxide at a lower decomposition temperature as compared to that reported in the literature $[1,2,5]$.

\section{Acknowledgement}

The authors gratefully acknowledge the financial supports provided by the National Science Council of the Republic of China under grant NSC96-2221-E-262-001.

\section{References}

[1] Kwon, Y. J., K. H. Kim, C. S. Lim and K. B. Shim, J. Ceram. Processing Research, 3, 3, 2002, pp.146-149.

[2]Chen, P. C., L. C. Hung, H. W. Fan and L. C. Lin, "Preparation of micro- and/or nano-zinc oxalate and zinc oxide powders", 2006 NATAS, West Ken turkey University, USA(CD-ROM)

[3]Carnes, C. L. and K. J. Klabunde, Langmuir, $16,3764-3772(2000)$.

[4]Komarneni, S., M. Bruno, E. Mariani, Materials Research Bulletin, 35, 1843-1847(2000).

[5]Kanade, K. G., B. B. kale, R. C. Aiyer, b. K. Das, , Materials Research Bulletin, 41, 590-600(2006).

[6]Hu, Z. D. J. E. Ramirez, B. E. H. Cervera, G. Oskam, P. C. Searson, J. phys. Chem. B, 109, 11209-11214(2005).

[7]Guo, L., S. Yang, C. Yang, P. Yu, J. Wang, W. Ge, G. K. L. Wang, Applied Physcis Letters, 76, 20, 2901-2903(2000).

[8]Kaneko, D., H. Shouji, T. Kawai, K. K. No., 
Langmuir, 16, 4086-4089(2000).

[9]Chen, Pao-Chi, Welly Shi, Ruby Du, and Vanessa Chen, Ind. Chem. Res., 47, 6336-6343(2008).

[10]Kakiuchi, K., E. Hosono, T. Kimura, J.

Sol-Gel Sci. Techn., 39, 63-72(2006).

[11]Kao, H. C. and W. C. Wei, J. Am. Ceram.

Soc., 83, 2, 362-368 (2000).

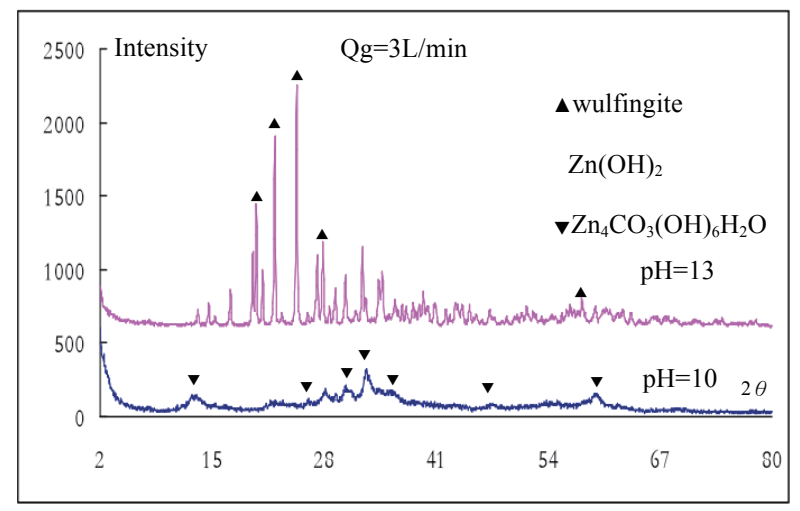

Fig. 1 XRD patterns for different precursors.

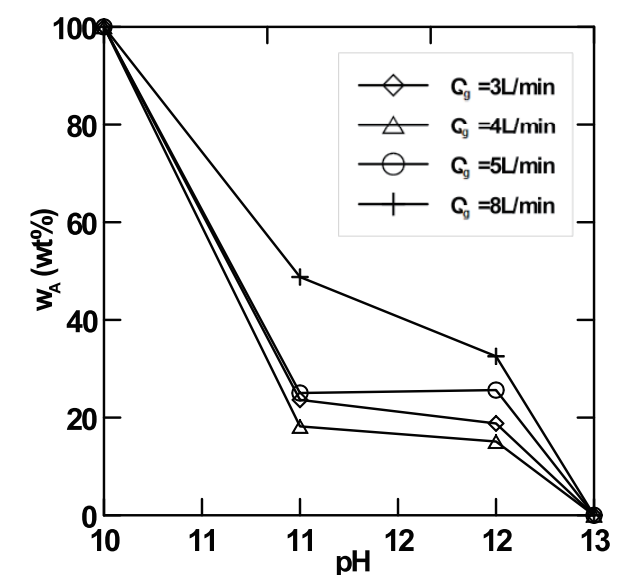

Fig. 2 A plot of composition $w_{A}$ vs. pH at various gas-flow rates.

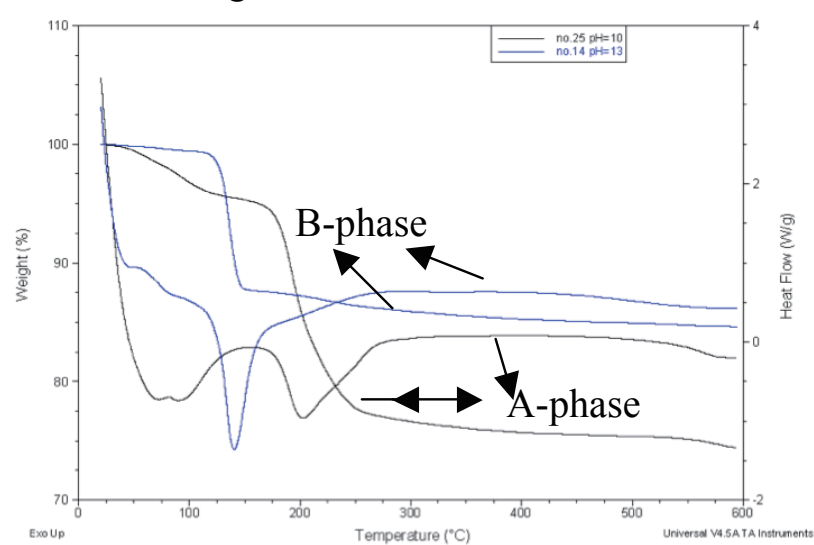

Fig. 3 TGA/DSC curves for different precursors.

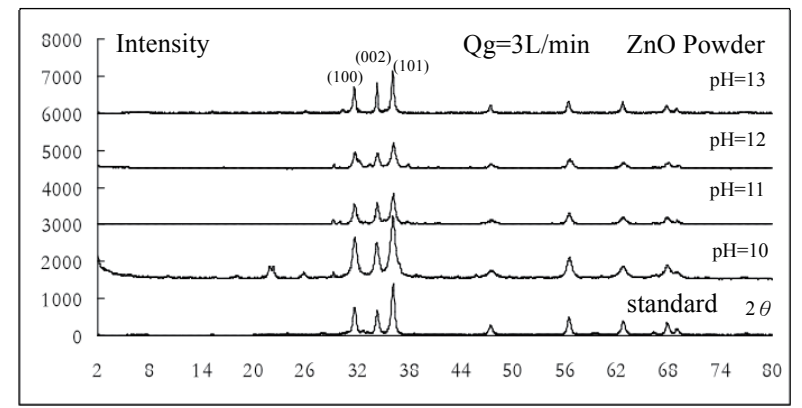

Fig. 4 XRD patterns for $\mathrm{ZnO}$ at different $\mathrm{pH}$ values compared with standard $\mathrm{ZnO}$ powder.

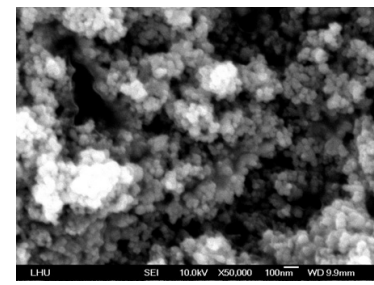

(a) $\mathrm{ZnO}$ from B-phase

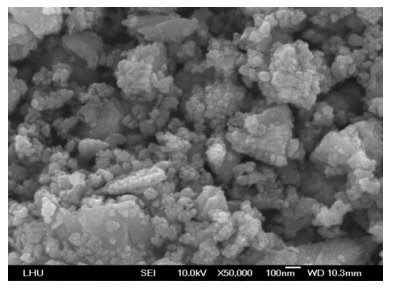

(b) $\mathrm{ZnO}$ from A-phase
Fig. $5 \mathrm{ZnO}$ obtained from different precursors.

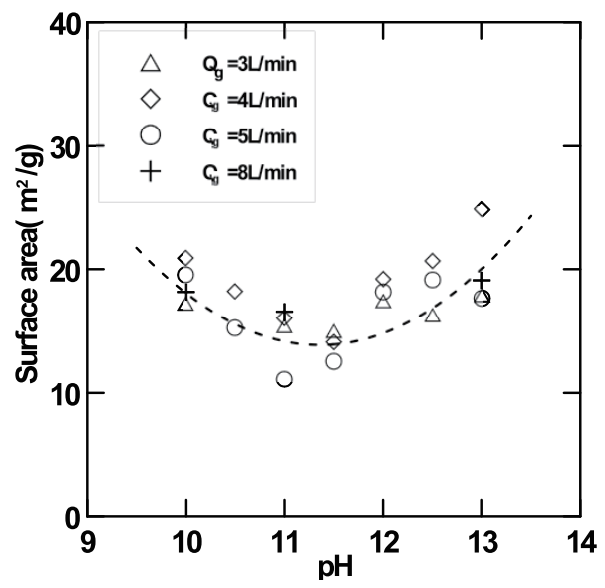

Fig. 6 A plot of Surface area vs. $\mathrm{pH}$ at different gas-flow rates, showing the sintering effect of $\mathrm{Zn}(\mathrm{OH})_{2}$.

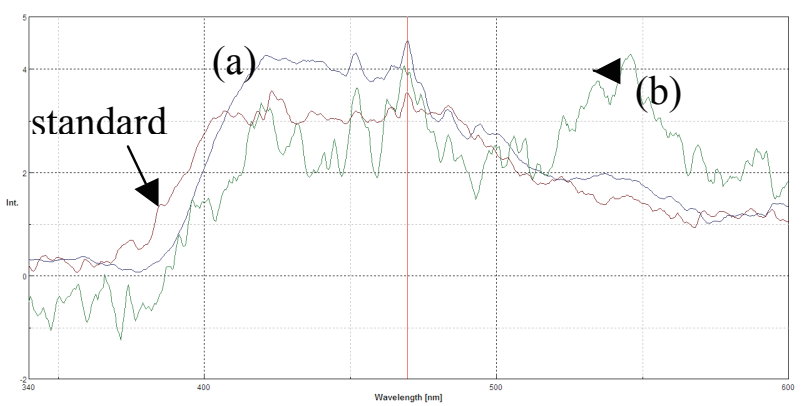

Fig. 7 PL spectrum for $\mathrm{ZnO}$ obtained for different precursors: (a) A-phase, $\mathrm{pH}=10$, $\mathrm{Q}_{\mathrm{g}}=4 \mathrm{~L} / \mathrm{min}, 260^{\circ} \mathrm{C}$ (No. 24); (b)B-phase, $\mathrm{pH}=13$, $\mathrm{Q}_{\mathrm{g}}=4 \mathrm{~L} / \mathrm{min}, 150^{\circ} \mathrm{C}(\mathrm{No} .8)$

(Received November 11, 2008; Accepted March 7, 2009) 